\title{
RECOGNITION AND PREVENTION OF MEDICATION ERRORS IN PEDIATRIC INPATIENTS: THE ROLE OF CLINICAL PHARMACISTS
}

\author{
Mustafa B. Al-Khyat ${ }^{1}$, Mohammed I. Aladul ${ }^{2,3}$ \\ ${ }^{1} \mathrm{Ibn}$ Al-Atheer Teaching Hospital, Nineveh Health Directorate, Mosul, Iraq, 41002. \\ ${ }^{2}$ College of Pharmacy, University of Mosul. Nineveh, Iraq, 41002. \\ ${ }^{3}$ College of Pharmacy, Ninevah University, Nineveh, Iraq, 41002.
}

*Corresponding author: m.i.m.aladul@uomosul.edu.iq

\begin{abstract}
Introduction: Medication errors (MEs) are considered preventable errors that may occur frequently during the treatment process with or without patient harm in addition to their economic consequence. MEs occur during prescribing, dose calculation, dispensing, or administration of medicine which could be made by any healthcare professional as a physician, pharmacist or nurse, or by the patient himself. Objective: To detect and report MEs in pediatric inpatients' medical records and potentially preventing these MEs by making recommendations/suggestions for healthcare professionals about the proper action needed to be taken. Methods: This was a prospective observational study, in which the medical records of admitted pediatric patients to Ibn Al-Atheer Teaching Hospital, Nineveh were reviewed to detect, report, and prevent MEs between the $1^{\text {st }}$ of January and the $30^{\text {th }}$ of June 2019. Results: Out of 6964 medical records reviewed by clinical pharmacists during the study period, 119 MEs were reported to healthcare professionals and prevented. $83 \%$ of detected MEs were dosing errors. The results of the Chi-square analysis showed that the highest percentage of dosing errors were associated with antibiotics $(p=0.0493)$. Furthermore, the results of Chi-square analysis showed that the highest percentage of dosing errors were seen in infants and toddlers $(p=0.011)$. Conclusion: This study highlighted the role of clinical pharmacists in recognizing, reporting and preventing MEs which are still occurring in every medical setting. Dosing errors were the most commonly occurring errors and antibiotics were the most frequent group of medicines involved in MEs.
\end{abstract}

Keywords: Medication errors, Pediatric, Clinical pharmacist 


\section{Introduction}

The treatment plan for each patient, is a multidisciplinary process involving prescribing, dispensing, administration of medicines and monitoring of the patient by healthcare professionals within the healthcare institute. This plan aims to promote patient's health and saving lives (Khowaja et al., 2008). However, medication errors (MEs) may arise during any step of the treatment plan and may potentially lead to treatment failure and/or patient harm (Ferner \& Aronson, 2006).

According to the National Coordinating Council for Medication Error Reporting and Prevention (NCCMERP), medication errors (MEs) are defined as "any preventable event that may cause or lead to inappropriate medication use or patient harm while the medication is in use" (Karna et al., 2012). Medication errors are multifactorial and might arise from (1) personal factors, such as lack of knowledge, prescribing problems, poor handwriting, inaccurate dose calculation, wrong strength or dosage form, incorrect method or route of administration, wrong patients order or dispense, mistakes in preparing \& labelling, or unclear direction of use, (2) environmental factors, such as inappropriate environment as workload noise or tension, bad store as heat or light, invalid packaging (Sinha et al., 2016; AL-Worafil, 2018). MEs are not only made by physicians, all healthcare providers (pharmacists, dentists and nurses), medicine's manufacturers and patients are involved in MEs (Karuppannan et al., 2013).

The consequences of MEs can range from simple unnoticeable errors to serious errors that lead to morbidity and mortality. In addition to the economic consequences of these errors that result from a prolonged hospital stay, need for further medical care and treatments, and decreased productivity (from time wasted in the hospital) (Walsh et al., 2017). Furthermore, MEs has psychological consequences in which the patients' confidence in their healthcare system would be compromised affecting patient's compliance and adherence to their treatment (Patanwala et al., 2010).

Medication errors are a very common problem worldwide. A recent study estimated that about 237million MEs occurred during the last year in UK's primary and secondary care settings and costs the UK National Health Service $£ 98$ million (Elliott, et al., (2021). Studies suggested that the incidence of MEs are three times higher $(1.1 \%)$ in the pediatric population in comparison with adults $(0.35 \%)$ (Kaushal et al., 2001; Payne et al., 2007; Baraki et al., 2018). Since pediatric medications are prescribed based on the patient's body weight or surface area that require precise dosage calculations. Furthermore, the availability or unavailability of multiple dosage forms/strengths would lead to confusion and errors. In addition to the incomplete development of the metabolic and elimination functions in premature infants up to the age of six months which would increase the chance of errors or toxicity in these patients (Kaushal et al., 2001).

In hospitals, clinical pharmacists are the most reliable source of information about medicines. They are trained to design the best treatment regimen for every patient to improve the patient's outcome and prevent MEs (Khayam, 2015). The importance of clinical pharmacist's role lies by working directly (touring) with physicians and liaising with other healthcare professionals in hospital wards during the process of medicines prescribing, dose calculation, preparation and administration and to identify, report and prevent MEs. Clinical pharmacist's role also involves direct observation and monitoring of prescribed medicines to the patient to ensure the proper utilization of medicine (Karuppannan et al., 2013; Dalton \& Byrne, 2017). Identification of MEs through a reporting system with analyzing the data 
helps the healthcare system to rebuild a safer system by modification of their protocols accordingly improve patient safety (La Pietra et al., 2005).

The aims of this study is detect and report MEs in pediatric inpatients' medical records and potentially preventing these MEs by making recommendations/suggestions for healthcare professionals about the proper action needed to be taken.

\section{Methods}

This study was approved by the Research Ethical Committee at Nineveh Health Directorate, Iraq (Ref. 14866). This prospective observational study was conducted between the $1^{\text {st }}$ of January and the $30^{\text {th }}$ of June 2019 at Ibn Al-Atheer Teaching Hospital, Nineveh, Iraq. This hospital is the main pediatric teaching hospital in Nineveh province, with 220 beds, consist of two general medical wards, preterm infants ward, intensive care unit (ICU), pediatric haematology and oncology ward and thalassemia ward. Within the two main wards, preterm infants ward and ICU (these wards would be collectively termed medical wards), where the study was conducted, twelve physicians were involved in prescribing medicines, while three clinical pharmacists were responsible for reviewing patients' medical records and treatment regimen, medication dispensing and patient counselling for patient's guardian or parents.

Pediatric patients aged from birth to 11 years admitted to the medical wards for at least two days during the study period were included in this study. Outpatients or patients with haematological or oncological diseases were excluded from the study. Pediatric patients were classified according to the International Conference on Harmonization of Technical Requirements for Registration of Pharmaceuticals for Human Use criteria: term newborn infants (0-27 days), infants and toddlers (28 days to 23 months), children (24 months to 11 years) (Singh, 2015).

\section{Data collection}

A special electronic form designed by the authors using Microsoft Excel 365 was used to collect data about reported MEs including (Patient's name, age, gender, weight, date of admission, chief complaint, diagnosis, number of medications, dose, dosage form and time and route of administration, type of MEs and the action taken for each ME). Reported MEs were classified into four main categories according to the Pharmaceutical Care Network Europe Foundation classification for MEs (Vm et al., 2018). These classes include (1) administration errors (in which the drug administered/used by a health professional/patient improperly), (2) dosing errors (in which doses used are either higher or lower than indicated for a particular patient), (3) interaction errors (in which a potential drug-drug and/or drug-food interaction are anticipated) and (4) prescribing errors (in which the prescribed drug, dosage form, route of administration or treatment duration are irrational). Healthcare professionals were informed about the MEs with a recommendation/ suggestion about the proper action needed to be taken to prevent MEs. 


\section{Data analysis}

Collected data from the electronic from were transferred from Microsoft Excel to STATA software for analysis. A descriptive statistical analysis (Chi-square test) was performed using STATA MP 13 software. $p$-values less than 0.05 were considered statistically significant.

\section{Results}

During the study period, 6964 patients were admitted to the medical wards at Ibn Al-Atheer Teaching Hospital, Nineveh. More than half $(55.6 \%)$ of the admitted patients were females, with a mean age of $4.57 \pm 2.55$ years. The mean period between admission and discharge of the patients were $3.6 \pm 1.6$ days. The main diagnosis/reason of admission of these patients were respiratory tract infections $(39 \%)$, gastroenteritis $(17 \%)$, urinary tract infections $(2.9 \%)$, sepsis $(2.5 \%)$, asthma $(2 \%)$, meningitis $(0.9 \%)$, cardiac diseases $(0.6 \%)$ and other less common diseases.

The medical records for these patients were checked by clinical pharmacists at the wards for potential MEs. In these records, the clinical pharmacists have detected 119 MEs in 119 patients' records, with an error rate of $1.7 \%$. The majority of these errors $(63 \%)$ were detected in male patients. The mean age of these (119) patients with detected MEs was $14.6 \pm 2.3$ months and the mean weight was $8.45 \pm 0.58 \mathrm{~kg}$. Table 1 shows the type and frequency of medication errors detected in this study and the action suggested/performed according to the guidelines and references used in pediatric medicine. In more than half of the recorded errors are high prescribed doses (dosing errors) and the action was taken by the clinical pharmacists were decreasing the dose of the medications.

Table 1 Types and frequencies of detected medication errors with suggested actions to prevent medication errors

\begin{tabular}{|c|l|l|l|l|}
\hline $\begin{array}{l}\text { Type of medication } \\
\text { errors }\end{array}$ & Number & Frequency & $\begin{array}{l}\text { Suggested actions to prevent } \\
\text { medication errors }\end{array}$ \\
\hline Administration errors & & 5 & $4 \%$ & $\begin{array}{l}\text { 2 changed to alternative medicines } \\
3 \text { changed the route of administration }\end{array}$ \\
\hline $\begin{array}{c}\text { Dosing errors (Total) } \\
\text { Low dose } \\
\text { High dose }\end{array}$ & 99 & $\begin{array}{l}83 \% \\
28.5 \%\end{array}$ & $\begin{array}{l}34 \text { increased the dose accordingly } \\
65 \text { decreased the dose accordingly }\end{array}$ \\
\hline Interaction errors & 34 & $54.5 \%$ & $\begin{array}{l}\text { 2 stopped the treatment } \\
\text { changed to alternative } \\
\text { changed the treatment frequency } \\
\text { to avoid concomitant administration }\end{array}$ \\
\hline Prescribing errors & 12 & $10 \%$ & & $\begin{array}{l}\text { 1 stopped the medicine } \\
\text { 1 changed to an alternative }\end{array}$ \\
\hline
\end{tabular}


Table 2 shows the results of the Chi-square tests. This test used to determine the independence of the characteristics of patients and their prescribed medications' groups with the type of MEs. Amongst the types of MEs, the highest percentage of MEs were dosing errors. The Chi-square analysis shows that the highest percentage of dosing errors were associated with the male gender $(p=0.340)$. Among the age groups, the results of Chi-square analysis show that the highest percentage of dosing errors were seen in infants and toddlers $(p=0.011)$. Nine categories of medications were detected in this study, namely; antibiotics, antiepileptics, antipyretics, antivirals, bronchodilators, cardiac agents, fluids and electrolytes, gastrointestinal agents and steroids. The results of the Chi-square analysis show that the highest percentage of dosing errors were associated with antibiotics $(p=0.0493)$.

Table 2: Comparison of patients' characteristics and their prescribed medication group and types of medication error

\begin{tabular}{|c|c|c|c|c|c|c|}
\hline $\begin{array}{l}\text { Characteristic } \\
\text { s }\end{array}$ & Total & $\begin{array}{l}\text { Administratio } \\
\mathrm{n}\end{array}$ & Dosing & $\begin{array}{l}\text { Interactio } \\
\mathrm{n}\end{array}$ & $\begin{array}{l}\text { Prescribin } \\
\mathrm{g}\end{array}$ & $\begin{array}{l}\text { Chi-square } \\
\text { tests of } \\
\text { independenc } \\
\text { e }\end{array}$ \\
\hline $\begin{array}{l}\text { Age groups } \\
\text { Child } \\
\text { Infant } \\
\text { Newborn }\end{array}$ & $\begin{array}{l}18 \\
(15.12 \% \\
) \\
69 \\
(57.98 \% \\
) \\
32 \\
(26.89 \%\end{array}$ & $\begin{array}{l}1(20 \%) \\
4(80 \%) \\
0(0 \%)\end{array}$ & $\begin{array}{l}15 \\
(15.5 \%) \\
52 \\
(52.53 \% \\
) \\
32 \\
(32.32 \% \\
)\end{array}$ & $\begin{array}{l}1(8.3 \%) \\
11(91.7) \\
0(0 \%)\end{array}$ & $\begin{array}{l}1(33.3 \%) \\
2(66.7 \%) \\
0(0 \%)\end{array}$ & $\begin{array}{l}X^{2}=21.3374 \\
p=0.011^{*}\end{array}$ \\
\hline $\begin{array}{l}\text { Gender } \\
\text { Female } \\
\text { Male }\end{array}$ & $\begin{array}{l}41 \\
(34.45 \% \\
) \\
78 \\
(65.55 \% \\
)\end{array}$ & $\begin{array}{l}3(60 \%) \\
2(40 \%)\end{array}$ & $\begin{array}{l}33 \\
(33.3 \%) \\
66 \\
(66.7 \%)\end{array}$ & $\begin{array}{l}3(25 \%) \\
9(75 \%)\end{array}$ & $\begin{array}{l}2(66.7 \%) \\
1(33.3 \%)\end{array}$ & $\begin{array}{l}X^{2}=3.3533 \\
p=0.340\end{array}$ \\
\hline $\begin{array}{l}\text { Medicine } \\
\text { groups } \\
\text { Antibiotics } \\
\text { Antiepileptics } \\
\text { Antipyretics } \\
\text { Antivirals } \\
\text { Bronchodilator } \\
\text { s Cardiac agents } \\
\text { Fluids and } \\
\text { electrolytes } \\
\text { Gastrointestina } \\
\text { lagents } \\
\text { Steroids }\end{array}$ & $\begin{array}{l}71 \\
(59.66 \% \\
) \\
16 \\
(13.44 \% \\
) \\
3(2.5 \%) \\
4 \\
(3.36 \%) \\
6(5 \%) \\
1 \\
(0.84 \%) \\
3(2.5 \%) \\
10 \\
(8.4 \%) \\
5(4.2 \%) \\
\end{array}$ & $\begin{array}{l}4(80 \%) \\
1(20 \%) \\
0(0 \%) \\
0(0 \%) \\
0(0 \%) \\
0(0 \%) \\
0(0 \%) \\
0(0 \%) \\
0(0 \%)\end{array}$ & $\begin{array}{l}60 \\
(60.6 \%) \\
13 \\
(13.1 \%) \\
2(2 \%) \\
4(4 \%) \\
4(4 \%) \\
1(1 \%) \\
2(2 \%) \\
9(9.3 \%) \\
4(4 \%)\end{array}$ & $\begin{array}{l}6(50 \%) \\
2(16.6 \%) \\
0(0 \%) \\
0(0 \%) \\
1(8.3 \%) \\
0(0 \%) \\
1(8.3 \%) \\
1(8.3 \%) \\
1(8.3 \%)\end{array}$ & $\begin{array}{l}1(33.3 \%) \\
0(0 \%) \\
1(33.3 \%) \\
0(0 \%) \\
1(33.3 \%) \\
0(0 \%) \\
0(0 \%) \\
0(0 \%) \\
0(0 \%)\end{array}$ & $\begin{array}{l}X^{2}=23.3311 \\
p=0.0493^{*}\end{array}$ \\
\hline
\end{tabular}




\section{Discussion}

The main reason behind medicines development is to improve the patient's outcome and relieve the ailment. Despite the rapid development in medicine production, therapeutic regimen designing and the introduction of electronic medical programs and applications within hospitals, MEs are still common in the healthcare system and a big concern in developed and developing countries. Drug-related complications like adverse events and side effects were further increased by MEs and that may need or prolong hospitalization with further resources to be used (Abubakar et al., 2014).

The results of this study showed that the rate of MEs are quite low (1.7\%) in comparison with other national and international studies. In Nori et al., (2014) study which was conducted in Sulaimani Pediatric Teaching Hospital, Sulaimani, Kurdistan Region, Iraq, showed that the percentage of MEs was very high (85\%) in 587 medication orders. Similarly, Al-Jeraisy et al., (2011) study, which was conducted at King Abdulaziz Medical City, Saudi Arabia, recorded MEs was also high (56\%) in 2,380 medical records. Furthermore, Khayam et al., (2015) study, which was conducted in tertiary care teaching hospitals (RMI) at Peshawar, Pakistan, showed that the percentage of MEs was $68 \%$ in 200 medical records. The reason for the low percentage of MEs in the current study might be due to the presence of clinical pharmacists who work side by side with physicians and other healthcare professionals within the hospital to provide the best care for patients. Although MEs are more common among pediatric patients than in adult patients in hospitals because more calculation and dilution of the prescribed doses for pediatric patients based on body weight are associated with the chance of errors (Fortescue et al., 2003). However, Mosah et al., (2012) study, which was conducted in Baquba Teaching Hospital, Diyala, Iraq, showed that the percentage of MEs in adult patients was (8.7\%) in 299 medication records, which is even higher than the results of this study.

The results of this study showed that dosing errors were the most commonly detected errors among pediatric patients. This result was in line with Nori et al., (2014), Al-Jeraisy et al., (2011) and Ghaleb et al., (2006) studies. This was attributed to the wide variation in body weight of patients, which ranges from about two kilograms in preterm infants to tens of kilograms in older children, the narrow therapeutic range of the drugs used in paediatrics which requires doses to be calculated individually based on patient age, weight or body surface area, and clinical condition. This careful and precise dosing calculation in a crowded environment with a heavy workload for long working hours for physicians would increase the chance of dosing errors in a hospital setting (Wong et al., 2004).

Barber et al., (1997) study showed that hospital pharmacists interventions for correcting/ amending dosing errors were much higher in paediatric wards in comparison to surgical, gynaecological and geriatric wards within a 10,000 beds' hospital in the UK. Several strategies were suggested to limit dosing errors in paediatric hospitals like computerized systems for prescribing (e.g., EMIS), electronic portable aids (e.g., tablets and mobiles), calculators and pre-calculated charts for each medicine containing the condition and the weight of the patients (Kaufmann et al., 2012). Refreshing lectures and summaries of paediatric medicine indications and doses for prescribers, and determination and follow up of the patient's weight by the nurse at the time of admission and during the stay would also decrease the rate of dosing errors (Foresman-Capuzzi, 2011; Merry \& Anderson, 2011). 
The results of this study also showed that MEs were higher in prescriptions for antibiotics than in other groups of medicines used. Since antibiotics were the most commonly prescribed medicines in pediatric hospitals and associated with a high rate of MEs even in developed countries like the UK and USA (Neubert et al., 2008; Condren et al., 2010; Ghaleb et al., 2010). This result was in line with Zeleke et al., (2014) study which found that MEs and specifically dosing errors were higher (54\%) in prescriptions for antibiotics (Zeleke et al., 2014). In contrast, the result of this study was not in line with Nori et al., (2014), Al-Jeraisy et al., (2011) studies, which found that MEs errors were higher in prescriptions for bronchodilators and electrolytes and fluids respectively (Al-Jeraisy et al., 2011; Nori et al., 2014).

\section{Limitations of the study}

This study has several limitations: first; that this study was conducted in one hospital and therefore generalization of the result must be made cautiously. Second; is that the study was conducted for six months which were the winter and spring season in the North of Iraq, which associated with more respiratory tract infections and therefore the results were skewed towards these medicines, however, at the end of June 2019, refurbishment and reconstruction of different wards begun at the hospital and result in termination of the study. Therefore, a longer duration of at least one year in different pediatric hospitals would give more precise and generalizable results.

\section{Conclusion}

This study highlighted the role of clinical pharmacists in recognizing, reporting and preventing MEs which are still occurring in every medical setting. The results suggested that dosing errors were the most common in this study, which can be limited by the inclusion of electronic aids and refreshing lectures and summaries that can be given by clinical pharmacists. Antibiotics were the most frequent group of medicines involved in MEs. This needs a more strict policy for antibiotic use and dosing in every hospital. The intertwined action of clinical pharmacists with physicians and other healthcare providers and with the patients would potentially eliminate MEs and improve patients' outcomes and eventually a successful treatment process.

\section{Acknowledgements}

The authors would like to acknowledge the clinical pharmacists in the medical ward at Ibn Al-Atheer Teaching Hospital for their support in this study, especially Raghad Salim, Zahraa Qusay, Ataa Abd Aziz and others who helped in the process of monitoring, detection and reporting medication errors during the study period.

\section{Conflicts of Interest}

The author declares no conflicts of interest. 


\section{References}

- Abubakar, A. R., Chedi, B. A., Simbak, N. B., \& Haque, M. (2014). Medication error: The role of health care professionals, sources of error and prevention strategies. J Chem Pharm Res, 6(10), 646-651.

- Al-Jeraisy, M. I., Alanazi, M. Q., \& Abolfotouh, M. A. (2011). Medication prescribing errors in a pediatric inpatient tertiary care setting in Saudi Arabia. BMC research notes, 4(1), 1-6.

- AL-Worafil, Y. M. (2018). Dispensing errors observed by community pharmacy dispensers in IBB-YEMEN. Asian J. Pharm. Clin. Res, 11(11).

- Baraki, Z., Abay, M., Tsegay, L., Gerensea, H., Kebede, A., \& Teklay, H. (2018). Medication administration error and contributing factors among pediatric inpatient in public hospitals of Tigray, northern Ethiopia. BMC pediatrics, 18(1), 1-8.

- Barber, N. D., Batty, R., \& Ridout, D. A. (1997). Predicting the rate of physician-accepted interventions by hospital pharmacists in the United Kingdom. American Journal of HealthSystem Pharmacy, 54(4), 397-405.

- Condren, M., Studebaker, I. J., \& John, B. M. (2010). Prescribing errors in a pediatric clinic. Clinical pediatrics, 49(1), 49-53.

- Dalton, K., \& Byrne, S. (2017). Role of the pharmacist in reducing healthcare costs: current insights. Integrated pharmacy research \& practice, $6,37$.

- Elliott, R. A., Camacho, E., Jankovic, D., Sculpher, M. J., \& Faria, R. (2021). Economic analysis of the prevalence and clinical and economic burden of medication error in England. BMJ Quality \& Safety, 30(2), 96-105.

- Ferner, R. E., \& Aronson, J. K. (2006). Clarification of terminology in medication errors. Drug safety, 29(11), 1011-1022.

- Foresman-Capuzzi, J. (2011). Delivering resuscitation medications to pediatric patients. Journal of Emergency Nursing, 37(2), 194-199.

- Fortescue, E. B., Kaushal, R., Landrigan, C. P., McKenna, K. J., Clapp, M. D., Federico, F., ... \& Bates, D. W. (2003). Prioritizing strategies for preventing medication errors and adverse drug events in pediatric inpatients. Pediatrics, 111(4), 722-729.

- Ghaleb, M. A., Barber, N., Franklin, B. D., \& Wong, I. C. K. (2010). The incidence and nature of prescribing and medication administration errors in paediatric inpatients. Archives of disease in childhood, 95(2), 113-118.

- Ghaleb, M. A., Barber, N., Franklin, B. D., Yeung, V. W., Khaki, Z. F., \& Wong, I. C. (2006). Systematic review of medication errors in pediatric patients. Annals of Pharmacotherapy, 40(10), 1766-1776.

- Karna, K., Sharma, S., Inamdar, S. H. I. V. K. U. M. A. R., \& Bhandari, A. N. I. L. (2012). Study and evaluation of medication errors in a tertiary care teaching hospital-a baseline study. Int $\mathrm{J}$ Pharm Sci, 4(5), 587-593.

- Karuppannan, M., Nee, T. K., Ali, S. M., Thong, W. K., \& Boardman, H. (2013). The prevalence of adverse drug event-related admissions at a local hospital in Malaysia. Archives of Pharmacy Practice, 4(4).

- Kaufmann, J., Laschat, M., \& Wappler, F. (2012). Medication errors in pediatric emergencies: a systematic analysis. Deutsches Ärzteblatt International, 109(38), 609.

- Kaushal, R., Bates, D. W., Landrigan, C., McKenna, K. J., Clapp, M. D., Federico, F., \& Goldmann, D. A. (2001). Medication errors and adverse drug events in pediatric inpatients. Jama, 285(16), 2114-2120.

- Khowaja, R. N., Merchant, R. J., Dias, J., Bustamante-Gavino, I., \& Malik, A. (2008). A systematic approach of tracking and reporting medication errors at a tertiary care university hospital, Karachi, Pakistan. Therapeutics and clinical risk management, 4(4), 673.

- Khayam, M. U. (2015). Medication errors assessment and prevention by a clinical pharmacist in pediatric wards of RMI Hospital Peshawar, KPK-Pakistan. Ann. Pak. Inst. Med. Sci, 11(3), 124-129.

- La Pietra, L., Calligaris, L., Molendini, L., Quattrin, R., \& Brusaferro, S. (2005). Medical errors and clinical risk management: state of the art. Acta otorhinolaryngologica italica, 25(6), 339.

- Merry, A. F., \& Anderson, B. J. (2011). Medication errors-new approaches to prevention. Pediatric Anesthesia, 21(7), 743-753.

- Mosah, H. A., Sahib, A. S., \& AL-BIATI, H. A. (2012). Evaluation of medication errors in hospitalized patients. Medicine Journal, 8(2). 
- Neubert, A., Sturkenboom, M. C., Murray, M. L., Verhamme, K. M., Nicolosi, A., Giaquinto, C., ... \& Wong, I. C. (2008). Databases for pediatric medicine research in Europe-assessment and critical appraisal. Pharmacoepidemiology and drug safety, 17(12), 1155-1167.

- Nori, D. O., Aziz, T. A., \& Hussain, S. A. (2014). Medication errors in pediatric hospitals. AASCIT, 1(4), 56-61.

- Patanwala, A. E., Warholak, T. L., Sanders, A. B., \& Erstad, B. L. (2010). A prospective observational study of medication errors in a tertiary care emergency department. Annals of emergency medicine, 55(6), 522-526.

- Payne, C. H., Smith, C. R., Newkirk, L. E., \& Hicks, R. W. (2007). 2.2 pediatric medication errors in the Postanesthesia care unit: analysis of MEDMARX data. AORN journal, 85(4), 731-740.

- Singh, J. (2015). International conference on harmonization of technical requirements for registration of pharmaceuticals for human use. Journal of pharmacology \& pharmacotherapeutics, 6(3), 185.

- Sinha, G., Acharya, L. D., Thunga, G., \& Mathews, T. (2016). A study of medication errors in general medicine wards of the South Indian tertiary care hospital. Asian Journal of Pharmaceutical and Clinical Research, 9(4), 196-200.

- Vm, J. F., Horvat, N., \& Tommy, W. (2018). Pharmaceutical Care Network Europe foundation. Classification for drug related problems revised, 2(2), 15-16.

- Walsh, E. K., Hansen, C. R., Sahm, L. J., Kearney, P. M., Doherty, E., \& Bradley, C. P. (2017). Economic impact of medication error: a systematic review. Pharmacoepidemiology and drug safety, 26(5), 481-497.

- Wong, I. C., Ghaleb, M. A., Franklin, B. D., \& Barber, N. (2004). Incidence and nature of dosing errors in paediatric medications. Drug safety, 27(9), 661-670.

- Zeleke, A., Chanie, T., \& Woldie, M. (2014). Medication prescribing errors and associated factors at the pediatric wards of Dessie Referral Hospital, Northeast Ethiopia. International archives of medicine, 7(1), 1-6. 